\title{
Heuristics are Tools for Uncertainty
}

\author{
Shabnam Mousavi ${ }^{1,2} \cdot$ Gerd Gigerenzer $^{2}$
}

Received: 7 June 2017/Accepted: 28 July 2017/Published online: 20 December 2017

(C) The Author(s) 2017. This article is an open access publication

\begin{abstract}
Heuristics are commonly viewed in behavioral economics as inferior strategies resulting from agents' cognitive limitations. Uncertainty is generally reduced to a form of risk, quantifiable in some probabilistic format. We challenge both conceptualizations and connect heuristics and uncertainty in a functional way: When uncertainty does not lend itself to risk calculations, heuristics can fare better than complex, optimization-based strategies if they satisfy the criteria for being ecological rational. This insight emerges from merging Knightian uncertainty with the study of fast-and-frugal heuristics. For many decision theorists, uncertainty is an undesirable characteristic of a situation, yet in the world of business it is considered a necessary condition for profit. In this article, we argue for complementing the study of decision making under risk using probability theory with a systematic study of decision making under uncertainty using formal models of heuristics. In doing so, we can better understand decision making in the real world and why and when simple heuristics are successful.
\end{abstract}

Keywords Heuristics · Uncertainty · Ecological rationality · Recognition heuristic

\section{JEL Classification B5}

This paper has benefitted from feedback by the participants in the Summer Institute for Bounded Rationality 2017 at MPIB in Berlin. We are thankful to Rona Unrau for her assistance. The usual disclaimer applies.

Shabnam Mousavi

shabnam@jhu.edu

1 Johns Hopkins University Carey Business School, 1625 Massachusetts Avenue NW, Washington, DC 20036, USA

2 Center for Adaptive Behavior and Cognition, Max Planck Institute for Human Development, Lentzeallee 94, 14195 Berlin, Germany 
It is worth reiterating that the economics of risk and uncertainty lost its vitality in a prison of methodology that did not admit the real world. Uncertainty pervades many important real-world phenomena that have received less attention from economics than they deserve.

Richard Zeckhauser, 2014.

\section{Taking Uncertainty Seriously}

Situation where one not only knows in advance the full set of options, consequences, and probabilities but also can compute the optimal course of action are situations of risk; examples are gambles and lotteries. Unknown probabilities create a situation of uncertainty. In The Foundations of Statistics, Savage (1954) derived subjective probabilities to treat uncertainty in analogy to risk. His Bayesian decision theory applies to a set of situations for which he used the term small worlds. He was clear that outside of small worlds his theory of subjective expected utility maximization has no normative force; that is, it cannot determine the best option. Savage gave two examples of situations where expected utility theory does not apply: planning a picnic and playing chess.

Planning a picnic is outside of his theory because one cannot know in advance all outcomes that might happen and therefore cannot determine the option that will maximize one's expected utility. Savage wrote it would be "utterly ridiculous" (1954, p. 16) to apply utility maximization to such situations of uncertainty. Yet exactly that has become common practice, as a glance in economic journals reveals.

Unlike planning a picnic and similar ill-defined problems, chess is a well-defined game where an optimal sequence of moves exists, so that a player cannot lose if following it. However, no human or machine can find the optimal sequence-it is computationally intractable (Partridge 1992). The problem is that chess has approximately $10^{120}$ different unique sequences of moves (Colley and Beech 1988), or plays of the game, which is a number greater than the total number of atoms in the universe. In fact, most interesting problems in machine learning are computationally intractable and thus need to be addressed using non-optimizing methods, including smart heuristics. Intractability is a second reason why expected utility maximization and its variants cannot lead to identifying the best course of action.

Savage's modest definition was not inherited by the many who interpret Bayesian decision theory as a theory for everything, thereby denying the usefulness of the distinction between risk and uncertainty. ${ }^{1}$ This denial impedes the fruitful application of economic theory to those important problems that are ill-defined or intractable. Moreover, modeling these situations as if they resembled situations of risk can create illusions of certainty. For instance, in 2003, the distinguished macroeconomist Robert Lucas declared that economic theory had learned its lesson from the Great Depression and succeeded in protecting us from future disaster: "Its central problem of depression-prevention has been solved, for all practical purposes,

\footnotetext{
${ }^{1}$ For instance, in The Analytics of Uncertainty and Information (2nd ed., 2013, Cambridge University Press), Bikhchandani, Hirshleifer and Riley introduce Knight's distinction between risk and uncertainty, and write: "In this book, we disregard Knight's distinction. For our purposes, risk and uncertainty mean the same thing." (p. 10). And they continue modeling all situations with subjective probabilities, referring to Savage (1954).
} 
and has in fact been solved for many decades."2 Five years later, the worst crisis since the Great Depression hit.

In what follows, we first define the difference between risk and uncertainty and then introduce heuristics as tools for dealing with uncertainty, provide a classification of heuristics, and explain the basic concepts of the emerging science of heuristics using the recognition heuristic as an example. This analysis explains why the view of heuristics in behavioral economics as inferior strategies resulting from agents' cognitive limitations is misleading. Taking heuristics seriously has implications for decision making, in both theory and practice.

\section{Risk $\neq$ Uncertainty}

The distinction between risk and uncertainty exists in various versions, most prominently in Knight (1921). Risky choices can be characterized either as lotteries or as hedging in financial markets and insurance, and choices under these two types of risk do not equate with choice under uncertainty. To distinguish risk from uncertainty, Knight focused on the question whether and how probabilities can be measured. Following the classical seventeenth- and eighteenth-century distinction between propensities and observed frequencies, Knight distinguished two kinds of measurable risk:

RISK-1: Propensities. Probabilities are known by design, that is, a priori, such as through constructing dice and roulette wheels or by programming slot machines. Historically, the propensity interpretation has its origins in gambling (Daston 1988).

RISK-2: Relative frequencies in the long run. Probabilities are estimated by counting events in a reference class, such as rain or mortgage default. Historically, the frequency interpretation of probability has its origins in mortality tables used to calculate life insurance and annuities (Daston 1988).

If neither propensities nor relative frequencies are or can be known in the long run, Knight referred to situations of uncertainty. Related terms are fundamental uncertainty and, in the NASA terminology popularized by former U.S. Secretary of Defense Donald Rumsfeld, unknown unknowns.

UNCERTAINTY: If (1) the set of options is not known or (2) the set of their consequences is not known or (3) the probabilities of these consequences are not known, or some combination of these, then the situation is one of uncertainty.

By probabilities we mean those that are measurable as propensities or long-run frequencies. Note that this definition of uncertainty is more explicit than Knight's in that it mentions not only that the probabilities cannot be measured empirically, as Knight put it, but also the possibilities that the set of options and their outcomes themselves may not fully be known in advance. This definition additionally makes clear that ambiguity-defined as unknown probability distributions over known outcomes, as in the Ellsberg Paradox-is only one aspect of uncertainty. Uncertainty, rather than ambiguity, is typical for entrepreneurial action and the

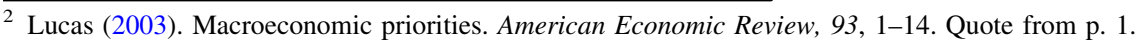


world of business in general. That is why heuristics are used frequently to achieve successful business choices (Mousavi and Gigerenzer 2014).

Risk is clearly defined, whereas uncertainty comes in many shades, ranging from out-of-sample prediction to fundamental uncertainty characterizing financial markets and human interactions. Uncertainty is not the same as risk, and it calls for its own formal, technical, and practical tools. Notably, under uncertainty, optimization is by definition infeasible, either because the full set of options and consequences or their probabilities cannot be known in advance or because the problem is computationally intractable. Although many decision theorists view this as an undesirable situation, for entrepreneurs, as Knight argued, it is a necessary condition for making profit.

\section{Tools for Uncertainty}

What tools are available to make decisions under uncertainty? It is surprising that in Knight's Risk, Uncertainty and Profit there is no attempt toward a systematic answer, let alone a formal analysis. He does use the terms intuitive feeling, judgment, hunch, and experience (e.g., p. 229-230), but little more. Similar to Knight, John Maynard Keynes argued that under uncertainty, decisions affecting the future "cannot depend on strict mathematical expectation, since the basis for making such calculations does not exist." 3 Yet what are the alternative tools? In his General Theory, Keynes suggests an answer: that people use animal spirits to deal with uncertainty, their innate urge to activity, spontaneous optimism, and hope, all of which make the wheels go round. Yet the reader is left in the dark about what exactly these animal spirits are and how to model these. In their book Animal Spirits, Akerlof and Shiller tried to dig deeper and distinguish five kinds of spiritsconfidence, fairness, corruption, money illusion, and stories. In their view, this motley bunch explains economic disasters from the Great Depression to the financial crisis of $2008 .{ }^{4}$ A list of five is better than none, yet their characterization of animal spirits as "noneconomic motives and irrational behaviors" is a step backwards from Keynes's position.

The major inspiration for a formal theory of decision making under uncertainty stems from a different source, Herbert A. Simon's work on heuristics. Simon (1989) explicitly posed the question: "How do humans reason when the conditions for rationality postulated by the model of neoclassical economics are not met?" The research on fast-and-frugal heuristics and their ecological rationality has been one of the major efforts to provide a systematic, empirically founded answer to this question (Gigerenzer, Todd, and the ABC Research Group 1999; Gigerenzer et al. 2011; Gigerenzer and Selten 2001). Before turning to this approach for analyzing action under non-reducible uncertainty, we briefly contrast it with the two major attempts within economics to understand how people deal with uncertainty.

\footnotetext{
${ }^{3}$ Keynes (1936), pp. 162-163.

${ }^{4}$ Akerlof and Shiller (2009), p. vviv.
} 
Some two decades after Knight, von Neumann and Morgenstern (1944) presented their axiomatization of "reasonable behavior." A decade later, Savage (1954) extended this framework by adding to it subjective probabilities, which remains to date the main pillar of mainstream economic theory (Giocoli 2011). ${ }^{5}$ Savage added a normative interpretation of the axioms, differing from von Neumann and Morgenstern's non-normative analysis, albeit restricted to the small worlds where situations of uncertainty are treated in analogy to risk. Three years later, Luce and Raiffa (1957) published Games and Decisions, with an orientation toward social science rather than mathematics. Looking back in 1988, Luce reflected, "'Our book introduced many people, especially in economics and business schools, to then new ideas of game and decision theory and did so in a way that was far easier to grasp than either the original monograph by von Neumann and Morgenstern (1944, The theory of games and economic behavior) or by Wald (1950, Statistical decision functions)". The terminology of game theory and decision theory is so prevalent in contemporary economics literature that it is hard to imagine that about only half a century ago it was entirely new to economists. Behavioral economists further modified the expected utility framework by adding free parameters in order to represent psychological factors, as in cumulative prospect theory and inequity aversion theory. These modifications have often been called models of bounded rationality. But note that although often presented as answers to Simon's question, they are not, and for two reasons. First, modifications of expected utility are as-if models in the sense of Milton Freedman, not descriptions or explanations of actual decision making in the sense of Simon. Second, they retain the optimization framework that assumes known risk rather than uncertainty.

The second answer has been the heuristics-and-biases program (Kahneman 2011; Kahneman et al. 1982) that became the foundation of the mainstream behavioral approach to economics. ${ }^{7}$ It has generated a long list of biases and associated heuristics that require correction in order to improve judgment and decisionmaking. Constructing de-biasing techniques provide the building blocks for policy programs that are designed to nudge people in certain directions. Over the past few decades, this program has been the dominant conceptualization of heuristics for a group of psychologists intent on showing that economic theory does not describe how humans make decisions. To do so, they typically used a content-free axiom or a rule of probability, added a story that was assumed to be of no relevance for rational judgment, and then tried to show that people's judgment deviates from the formal rule. Following content-blind rules was considered the only rational behavior, and systematic deviations between judgment and rule were interpreted as fallacies of judgment. Conlisk (1996) listed 22 such "cognitive illusions"; behavioral economists have since added many more. In contrast, psychological research outside the heuristics-and-biases framework has shown that the norms proposed are

\footnotetext{
5 Maclusky (2002) would object to the term mainstream economics being equated with this practice. She emphasizes that the accurate phrase is Samuelsonian economics, named after Paul Samuelson's dominant redefinition of economics.

6 See http://garfield.library.upenn.edu/classics1988/A1988M687100001.pdf.

7 The most comprehensive text on virtually all branches of behavioral economics is Dhami (2016).
} 
questionable from both a statistical and a psychological point of view and has demonstrated how to make allegedly stable illusions disappear (e.g., Gigerenzer 2000; Hertwig and Gigerenzer 1999). Moreover, some of the alleged systematic errors-including overweighting of small risks and underweighting of large ones, overconfidence, misperceptions of randomness, and the hot hand fallacy-have been shown to be based on errors in the statistical thinking of the researchers rather than of John Q. Public (e.g., Gigerenzer et al. 2012; Hahn and Warren 2009). These results can be seen as a rehabilitation of the rationality of Homo sapiens, who has been misleadingly compared to Homer Simpson (Thaler and Sunstein 2008). They also indicate that what became mainstream behavioral economics has not addressed the question of how people deal with uncertainty and has mistaken human intelligence for irrationality. All in all, the key methodological limits of the heuristics-and-biases program have been, instead of formal models of heuristics, (1) the use of one-word labels (availability; representativeness), which enable almost everything to be explained post hoc in the absence of predictive power, and (2) the use of narrow norms to understand the rationality of behavior, which are not sufficient for governing successful decisions under uncertainty (Gigerenzer 1996).

In sum, the standard approach of economic theory in dealing with uncertainty is to treat uncertainty in analogy to risk in order to hold on to optimization models. One of the few exceptions is the study of ambiguity, which applies to unknown probabilities but assumes known options and consequences. The heuristics-andbiases program has criticized the descriptive reality of the optimization framework but uncritically accepted it as normative standard, thus also ignoring situations of uncertainty where one cannot know ahead what the best action is. Simon's call for modeling the process of decision making under uncertainty was answered by neither of these two programs. Neither of them takes heuristics seriously or acknowledges that uncertainty can make heuristics necessary.

We are not the first to draw connections between Simon's attempt to develop realistic notions of rationality and the Knightian notion of uncertainty. Bewley (1987) built a Knightian decision theory, where in one case Knightian behavior and Simonian satisficing coincide. In this theory, action under uncertainty simply follows enough knowledge, generation of which involves some amount of intuition. This knowledge is not complete, as under risk, but good enough for the decision maker to act upon, an actionable state of knowledge. ${ }^{8}$ This intuition-based process connects with the heuristics framework for understanding decision making under uncertainty. Recall that Knight maintained that uncertainty alone, not risk, is relevant to business and economic decision making, and to making profit. One of the three notions of "inertia" in Bewley (1986) comes closest to our intended meaning of the process of heuristic decision making under uncertainty:

The third approach to inertia...makes a slight concession to bounded rationality in that it recognizes that a decision maker cannot possibly formulate a lifetime plan covering all contingencies. The disadvantage of bounded rationality is that it makes the concept of rational behavior very

\footnotetext{
8 Akin to actionable data in analytics, which refers to the amount of data that provides enough insight and clarity for decision makers to act upon.
} 
ambiguous. The best one can do is to imagine what a sensible, self-interested and boundedly rational person might do. I simply tell a plausible story in which inertia may be identified. I assume that the decision maker continually makes approximate plans. The inertia assumption is that these plans are abandoned only if doing so is judged necessary for an improvement. This picture of reality motivates a loose definition of inertia... which should be used when applying the [Knightian decision] theory. (pp. 8-9; emphasis added)

Bewley (1986) replaced the assumption of completeness with that of inertia, which in turn allows for intransitivity without loss of rationality and captures situations with changing goals. Our configuration of a suitable notion of rationality in the study of heuristic decision making, however, is diametrically different. We define an ecological notion of rationality that is achieved through a functional match between the heuristic strategy and the task environment. This configuration is much in line with Vernon Smith $(2003,2008)$, who shares our understanding of the role of heuristics (Mousavi and Kheirandish 2014; Mousavi et al. 2017). It allows us to provide rational explanations for ignoring information and thus understanding cases in which "less can be more".

\section{Classification of Heuristics}

On a daily basis, people make both important and inconsequential decisions under uncertainty, often under time pressure with limited information and cognitive resources. The fascinating phenomenon is that most of the time, a majority of people operate surprisingly well despite not meeting all requirements of optimization, be they internal (calculative abilities) or external (information access). They do so using rules of thumb that do not require complete information search or exhaustive calculations. In other words, people use heuristics. There exists a large empirical literature that documents in what situations people rely on what heuristics (e.g. Gigerenzer et al. 2011).

All heuristic rules can be seen as tools in the mind's adaptive toolbox, that also contains non-heuristic rules such as optimization. Whereas optimization adheres to an absolute sense of rationality according to a given set of axioms with presumed normative appeal, heuristic-based decision making is assessed on the basis of its match with the environment in which it is utilized and achieves different degrees of ecological rationality according to the attained match.

Heuristics per se are neither good nor bad. They can be evaluated only with respect to the environment in which they are used. The more functional the match is between a heuristic and the environment, the higher the degree of ecological rationality of the heuristic. The functionality of this match is verifiable by the extent of its success rather than fulfillment of coherence requirements. Studying fast-andfrugal heuristics and their ecological rationality has shaped the research at the Center for Adaptive Behavior and Cognition of the Max Planck Institute for Human Development over the past two decades (Gigerenzer et al. 2011). This investigation involves three aspects of heuristic decision making. First, studying the adaptive 
cognitive toolbox of individuals or institutions and specifying the building blocks of the heuristics they use constitute the descriptive research. Second, the conditions under which a heuristic is successful, that is, its ecological rationality, shapes the normative aspect. The third aspect involves intuitive design, that is, developing decision tools and aids in the form of heuristics that work well in a given environment or designing environments that trigger the use of certain desirable heuristics. Models of heuristic decision making emerge from observation and experimentation, resulting in a description of the underlying processes that generate final choices instead of focusing on outcomes only and reconstructing mathematically coherent as-if models that disregard actual stages of cognitive and behavioral mechanisms. Logic is useful but too narrow to account for the entire range of purposeful behavior (Mousavi and Gigerenzer 2011; Neth and Gigerenzer 2015).

Definition Heuristics are adaptive tools that ignore information to make fast and frugal decisions that are accurate and robust under conditions of uncertainty. A heuristic is considered ecologically rational when it functionally matches the structure of environment.

The simplicity of heuristics is the very reason for their robustness; it avoids finetuning of parameters that can cause large estimation error under uncertainty, and particularly under changing environmental conditions. Heuristic search rules can stop the search for information before all available or attainable information is examined. The choice of heuristic rules does not require full deliberation, notwithstanding the fact that heuristics can be brought to consciousness, formulated, and explicitly taught and/or learned.

The ecological rationality of a decision rule is assessed based on norms that are sensitive to the content of the problem and the context of the situation. The mapping between the task environment and the heuristic strategy is neither onto nor one-toone. Notice that a function needs to be onto and one-to-one to be invertible and oneto-one to be reversible. Constructivist rationality relies on the existence of reversible functions to reconstruct the steps towards a certain goal after observing the final decision. Evaluating heuristics based on their ecological rationality removes the restrictions imposed on evaluation of strategies according to the criteria of neoclassical rationality. Moreover, the belief that decisions should be ecologically rational directly forfeits the normativity of the constructivist approach to rationality where it pertains to developing behaviorally-based theories of decision making. It remains true, however, that constructivist rationality is a useful tool for decision scientists to generate as-if accounts as well as in making decisions in situations of risk. The in Vernon Smith's view broadly Hayekian distinction between these two forms of rationality, constructivist and ecological, in economics formed the title of his Nobel Prize lecture (2002). The juxtaposition with a psychology-based approach to ecological rationality is further discussed in Mousavi and Kheirandish (2014) and Mousavi et al. (2017).

Attainment of exhaustive information followed by optimal weighing of it is a pillar of valuation methodology and decision-making models in mainstream economics. To highlight the different approach afforded by the study of heuristic decision making, we introduce a classification of heuristics below, where each class 
emanates from a non-exhaustive, empirically based means of searching for and weighing information, into the process of decision making (Gigerenzer and Gaissmaier 2011). In the classification presented subsequently each class highlights a main characteristic of how humans deal with information, namely recognition ability, sequential search, satisficing, and equal weighting. These processes are not limited to situations under uncertainty. In fact, heuristics in each class can be used in both risky and uncertain situations.

CLASS-1: Recognition-based choice. Object recognition, such as brand name and face recognition, is a basic cognitive capability. This capability can be exploited by heuristics for making good choices with minimum knowledge. The simplest in this class is the recognition heuristic, which applies to choices between two (or more) objects and can be used when one option is recognized but the other is not, where recognition marks the distinction between a previously experienced versus a novel object (Goldstein and Gigerenzer 2002). In the simplest case, if the recognition validity is substantial (see below), the heuristic bets that the recognized object has a higher value with respect to a criterion than the unrecognized object. All information beyond recognition is ignored. The fluency heuristic is another heuristic in this class, and applies to situations where both objects are recognized, but one more quickly (Schooler and Hertwig 2005). It has been argued that fluency correlates directly with currency valuation, and valuation in IPO markets (Alter and Oppenheimer 2006, 2008). The fluency heuristic is not to be confused with the recognition heuristic, which is a binary ability, whereas there are various levels to fluency. For example, money fluency refers to being more or less familiar with one currency compared to another. The recognition heuristic will be discussed in more detail below.

CLASS-2: Sequential consideration of reasons. It has been well documented that experts and laypeople often go through reasons sequentially and stop after one reason has been found that enables a decision to be made, rather than trying to add and weigh all reasons simultaneously. After the order of reasons is set based on their validity or some other ordering principle, information is sought piece-by-piece and examined according to a goal-driven fulfillment of a criterion. Only if the examination of the first piece of information is not sufficiently decisive will the next piece of information be considered, and so forth. An example is the priority heuristic (Brandstätter et al. 2006), a lexicographic model for preferential choice that provides a heuristic-based alternative to the optimization-based expected utility models of choice between lotteries. The priority heuristic is both simple and powerful. It logically implies choice outcomes that are categorized as anomalies in the expected utility framework, such as the Allais paradox, the certainty effect, and the fourfold pattern of risk attitudes (Katsikopoulos and Gigerenzer 2008). ${ }^{9}$

CLASS-3: Satisficing strategies start with setting an aspiration level and stop search when the first object is encountered that satisfies the aspiration level. As opposed to Class-2 heuristics, there is no prespecified order to the search and examination of information. The aspiration level, however, can be subject to adjustment as the examination of information proceeds (Selten 2001). Proposed by

\footnotetext{
9 See Mousavi et al. (2016) for a presentation of the priority heuristic in a relatable form for economists.
} 
Herbert Simon (1956), the satisficing heuristic has since inspired models of boundedly rational behavior and is well known in economics. It describes, for instance, how German car dealers price second-hand BMWs (Artinger and Gigerenzer 2016) or how commercial developers choose building locations (Berg 2014).

CLASS-4: Equal weighing schemes ${ }^{10}$ forgo the estimation and assignment of "optimal" weights to pieces of information (known as cues in psychological vocabulary, payoffs in economics, and returns in finance). The rationale is to avoid large estimation error due to overfitting. In the absence of reliable assessment of the relative importance of different components, a condition that arises from uncertainty, agents often rely on heuristics such as tallying or equal allocation of resources among available options. Consequential decisions under time pressure in, for instance, emergency rooms (Kattah et al. 2009), non-stationary environments such as stock markets (DeMiguel et al. 2009), and human interaction such as parental investment (Hertwig et al. 2002) have been modeled by allocation of equal weights.

\section{An Illustration: The Recognition Heuristic}

In this section, we illustrate the study of the adaptive toolbox by one of the most frugal heuristics, the recognition heuristic (Class-1 above). We define the heuristic, its ecological rationality, the evolved cognitive capacities it exploits, and the conditions for a "less-is-more" effect. We then report on studies that tested its performance in dynamic environments where uncertainty is irreducible: sports and financial investment.

Companies invest large sums in advertising in order to increase their brand name recognition. As illustrated by the provocative Benetton campaign several decades ago, when the ads pushed Benetton into the top-five best-known brand names worldwide, sales increased by a factor of ten (Toscani 1997). By investing in brand name recognition, companies bet that consumers tend to buy products they have heard of-which is an instance of relying on the recognition heuristic.

In general, recognition is an evolved cognitive capacity. Name and face recognition are examples. Recognition is typically a binary judgment-having heard of a brand or not-and different from recall. Recall presumes mere recognition and concerns features of the recognized object, such as a company's current stock price. The human brain has a vast capacity for recognition. For instance, when exposed to 10,000 pairs of words, sentences, and pictures, people have been shown to correctly distinguish novel from experienced words or images with more than 85\% accuracy (Shepard 1967). The recognition heuristic exploits this vast capacity by drawing inferences from the fact that one has heard of some objects or brands, and not of others. For the simplest case of choosing between two

\footnotetext{
${ }_{10}$ Perceivably, equal weighing is a special case of a larger class of heuristics with rules that assign simple weights to cues, a direction for future explorations.
} 
objects, the recognition heuristic is defined as follows (Goldstein and Gigerenzer 2002, p. 76):

Recognition heuristic: If one of two objects is recognized and the other is not, then infer that the recognized object has the higher value with respect to the criterion.

The heuristic is a single-variable decision rule. As with every heuristic, its success depends on the structure of the environment, here on the correlation between recognition and a criterion, such as quality or performance. The study of ecological rationality identifies such structures.

\section{Ecological rationality: The recognition heuristic is ecologically rational if} $\alpha>.5$.

The recognition validity $\alpha$ is defined as $\alpha=R /(R+W)$, where $R$ is the number of correct (right) inferences the recognition heuristic would achieve across all pairs in which one object is recognized and the other not, and $W$ is the number of incorrect (wrong) inferences under the same circumstances. The expected proportion of correct inferences $\mathrm{f}(\mathrm{n})$ in a set of $N$ objects of which $n$ are recognized is:

$$
f(n)=2\left(\frac{n}{N}\right)\left(\frac{N-n}{N-1}\right) \alpha+\left(\frac{N-n}{N}\right) \times\left(\frac{N-n-1}{N-1}\right) \frac{1}{2}+\left(\frac{n}{N}\right)\left(\frac{n-1}{N-1}\right) \beta .
$$

Consider the right part of the equation. The first term accounts for the correct inferences made by the recognition heuristic, calculated from the proportion of times the recognition heuristic applies, that is, when one object is recognized and the other not, multiplied by the recognition validity $\alpha$. It shows that the recognition heuristic can be used most often when $n=N / 2$, that is, under "semi-ignorance". The middle term represents the correct inferences from guessing, that is, when neither object is recognized. The right-most term specifies the proportion of correct answers when knowledge beyond recognition is used, calculated from the proportion of times the recognition heuristic does not apply because both objects are recognized multiplied by the knowledge validity $\beta$. The latter is defined as the proportion of correct answers among all pairs where both objects are recognized. Note that all parameters- $\alpha, \beta, n$, and $N$-can be empirically measured in an experiment; no parameter fitting is needed.

Equation (1) has a counterintuitive implication: a less-is-more effect. Under specifiable conditions, individuals who know less can make more accurate inferences than do individuals who know more. Under the assumption that $\alpha$ and $\beta$ are constant, one can derive the following result (Goldstein and Gigerenzer 2002):

\section{A less-is-more effect occurs if $\alpha>\beta$.}

For instance, if $\alpha=.8$ and $\beta=.6$, then an individual who recognizes only $50 \%$ of the $N$ objects (and knows nothing about the others, by definition), will get about $68 \%$ of the inferences correct (Eq. 1), while an individual who recognizes all $100 \%$ of the objects will get $60 \%$ correct (that is, $\beta$ ). A less-is-more effect is a strong prediction, and it has been empirically supported in a number of experiments that 
showed that relying on the recognition heuristic can outperform relying on more knowledge (e.g., Gigerenzer and Goldstein 2011; Marewski et al. 2010). In fact, an observed less-is-more effect originally led to the discovery of this heuristic. For his dissertation, Hoffrage (1995) needed two sets of questions - a difficult and an easy one-for German students, to set the stage for testing an independent theory. In the first set, he combined the largest U.S. cities into pairs and asked which city has the larger population, doing the same in the second set but using the largest German cities. He expected that the proportion of correct answers would be higher in the latter set because students knew more facts about these than about the U.S. cities. In fact, the German students made slightly more accurate inferences about U.S. than German cities-despite knowing less. This puzzling result has since been explained: The Germans could use the recognition heuristic for the U.S. cities because the ones that they were familiar with were generally the largest, whereas their knowledge of all the German cities prevented them from doing so. The above analysis explains when this less-is-more effect occurs and its precise expected size.

These initial results generated a large body of literature investigating when people use this heuristic and the conditions of its ecological rationality, including several special issues of Judgment and Decision Making (Marewski et al. 2010, 2011). A review of the existing empirical studies showed that individuals' reliance on the recognition heuristic is sensitive to its ecological rationality in the specific tasks, with a Pearson correlation of $r=.57$ between the proportion of judgments consistent with the recognition heuristic (accordance rate) and the recognition validity (Gigerenzer and Goldstein 2011).

In general, a heuristic rule must be evaluated across domains so that its ecological rationality can be measured. However, a domain can change its structure over time. This makes the inquiry of the ecological rationality of a heuristic a dynamic pursuit subject to constant revision. This dynamism of rationality implies the need for norms that remain sensitive to the content of the problem at hand as well as the structure of the environment. Such ecological norms are in stark contrast with the logical norms of utility maximization, in which autonomy of the best solution from content and context is viewed as a major methodological strength. In instable, quickly changing environments where no optimal algorithm is known, simple heuristics can be efficient, as we next show in two examples. A common assumption is that more information and calculation lead to better prediction. Yet in highly dynamic situations, less of the two can be more successful.

\section{Decision Making in Dynamic Environments}

Predicting Wimbledon. How can the winners of the Wimbledon Gentleman Singles matches (128 contestants, 127 matches) be best predicted? Prediction of future outcomes, such as the results of sport matches, fits the criteria of uncertainty, whereas the original studies of Goldstein and Gigerenzer (2002) were conducted in domains with static criteria, where uncertainty existed only in the absence of knowledge. In the fast-moving world of tennis, heroes rise and fall quickly, and by 
the time their names enter the recognition memories of the public, their prowess may already be fading.

Serwe and Frings (2006) surveyed amateur tennis players and laypeople (nontennis players) on whether they had "already heard of" each of the 2003 Wimbledon contestants. The amateurs recognized on average $48 \%$ of the players, and the laypersons only $9 \%$, with a recognition validity of .73 and .67 , respectively. Thus, the amateurs could apply the recognition heuristic at an almost optimal level (50\% recognition) and with a good recognition validity (see Eq. 1), while the laypersons could use it rarely, and if so, with a lower recognition validity. Next, the players were ranked according to the number of participants who had heard of them; the prediction rule was that each match would be won by the player with the higher recognition ranking. These predictions based on "collective recognition" were compared with predictions based on professional rankings, namely, the ATP Entry Ranking and the ATP Champions Race. Professional rankings are information intensive in that they acquire and integrate the past year's performance of all players to calculate their ranking. The prediction rule was the same as for collective recognition: The player with the higher ranking would win. How well did recognition predict the winners of the individual games compared to the ATP rankings?

Figure 1 shows that the two ATP rankings predicted $66 \%$ and $68 \%$ of the winners correctly, which is better than chance $(50 \%)$. In contrast, the collective recognition of the amateurs predicted $72 \%$. This result was obtained even though the amateurs had never heard of about half of the players-or better said, because of that. The ranking based on laypeople's recognition performed worse than the amateurs', as can be derived from Eq. 1. Nonetheless, it matched the performance of the ATP Entry Ranking.

Hence, the collective version of the recognition heuristic can be used as a successful inferential rule, but do individual people actually use it? Serwe and

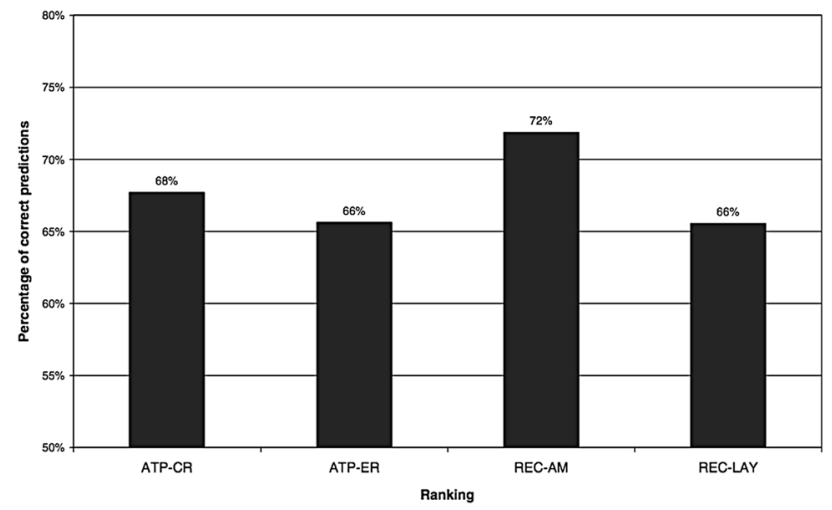

Fig. 1 Predicting Wimbledon 2003 by mere name recognition. Correct predictions of the official ranking procedures ATP Champions Race (ATP-CR) and ATP Entry Ranking (ATP-ER) compared to the recognition ranking for amateurs (REC-AM) and laypeople (REC-LAY). Relying on the recognition heuristic (here: collective recognition) of amateur players predicted the winners as well as and better than information-intensive ATP rankings. Adapted from Serwe and Frings (2006) 
Frings (2006) also tested whether laypeople and amateurs actually rely on the recognition heuristic and found that their choices were consistent with the heuristic in 88 and $93 \%$ of the cases, respectively. A replication study found essentially similar results for Wimbledon 2005 (Scheibehenne and Bröder 2007). In both studies, the recognition heuristic proved an effective inferential tool for the dynamic situations of uncertainty in the domain of sport events.

Performance in financial markets. The idea of pitting the recognition heuristic against the uncertainty of the stock market can have two underlying motivations. First, customers tend to choose products they have heard of, and stocks are products whose prices are functions of human choice. Second, several successful investment experts such as Peter Lynch have suggested that lack of name recognition is frequently grounds for eliminating stocks from consideration (Lynch 1994). ${ }^{11}$ In 1996, a group of economists and psychologists built investment portfolios of the stocks of companies whose names were highly recognized, either by the public or by experts, in Germany as well as in the US (Borges et al. 1999). The combination of foreign/domestic and expert/laypeople recognition made for eight recognition portfolios (Fig. 2). Each was defined as the stocks that $90 \%$ or more of the group recognized. Their performance was then tested against the market index (Dow 30 or Dax 30), mutual funds (Fidelity Growth Fund or Hypobank Equity Fund), chance portfolios (average return of 5000 randomly drawn portfolios), and unrecognized stocks (0-10\% recognition rates). All portfolios were completed on the day of the recognition test, December 13, 1996, and the performance was measured 6 month later.

Figure 2 shows that the high-recognition portfolio performed at par with all contestants. In six out of the eight tests, it outperformed the market index, the mutual funds, and the chance portfolios. In every case, it outperformed the portfolio of unrecognized stocks. The advantage of the recognition portfolio was most visible where ignorance was highest, that is, in international recognition, specifically for U.S. citizens' name recognition of German stocks. Further tests of the recognition heuristic in stock-picking contests led to comparable results (Ortmann et al. 2008).

The question of the ecological rationality of recognition portfolios in the stock market, however, has not been answered. Andersson and Rakow (2007) reported that their replication efforts had produced mixed results on the performance of the recognition-based portfolio and that they were not able to consistently replicate those of Borges et al. (1999). Revisiting of the subject led to determining the role of bear versus bull markets in the success of such portfolio: The recognition-based portfolio may be likely superior to some passive portfolios such as the market index in a bull market, but not in a bear market. The suitability criteria for applying the recognition heuristic to the financial domain thus far remains a matter of further empirical investigation.

\footnotetext{
11 https://soundcloud.com/value-investing-world-1/peter-lynch-1994-talk.
} 


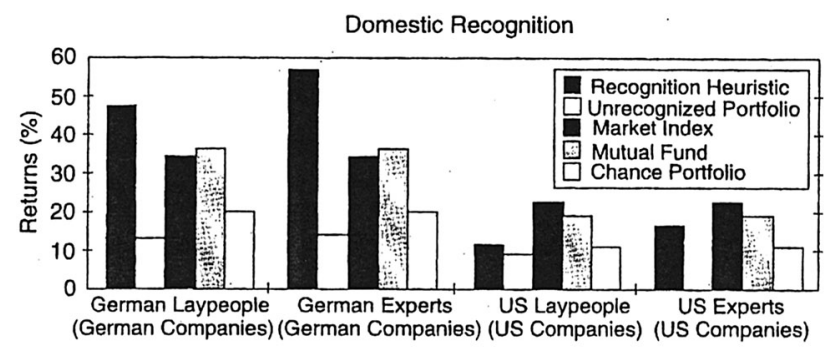

International Recognition

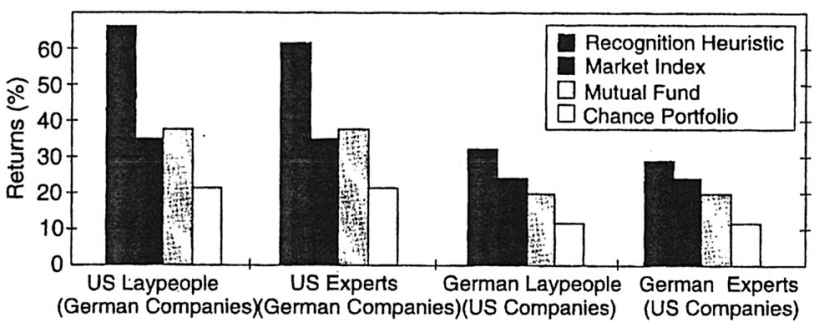

Fig. 2 Performance of the recognition heuristic for companies with the highest recognition rates by German laypeople, German experts, U.S. laypeople, and U.S. experts. Domestic recognition means that the recognition rates of Germans for German stocks, and of U.S. citizens for U.S. stocks. International recognition means Germans' recognition rates of U.S. stocks, and U.S. citizens' recognition rates of German stocks. Results are for the six months following the recognition test. For instance, in the top left panel, the recognition portfolio consisted of all German stocks that at least $90 \%$ of 180 German laypeople recognized by name. After the test period of 6 months, it resulted in a gain of $47 \%$, compared to $13 \%$ for the portfolio of the least recognized stocks (10\% or less recognition rate), $34 \%$ for the DAX-30, $36 \%$ for the Hypobank Investment Capital Fund, and 22\% for random stock portfolios. From Borges et al. 1999

\section{Why Should Economists Care?}

Contrary to the mainstream psychological account of heuristics and biases, we argued that people's use of heuristics under uncertainty cannot be universally attributed to cognitive limitations. Rather, heuristics can be ecologically rational. That implies that much of the critique of the irrationality of people posited by behavioral economists needs to be rethought (Gigerenzer 2015). A framework that allows for this pursuit is the study of fast-and-frugal heuristics, with a "toolbox perspective" on the problem of choice. The toolbox approach removes several restrictive requirements of mainstream economic theory without abandoning optimization as one of the many tools, and has generated realistic models of choice behavior under uncertainty.

In this article, we showed that there is an alternative to the customary treatment of uncertainty as an undesirable property of a situation. This alternative exists both for the agent who wants to reduce uncertainty to certainty by gaining more information and knowledge and for the modeler who routinely characterizes uncertainty as probabilistic risk calculation in order to make it measurable. We connected Knight's characterization of uncertainty as a necessary element for 
generating profit with heuristic processes of information as a basis for choice. This underexplored area is a potential path for building behavioral-based theories of human action that neither are as-if nor deny that people need to deal with uncertainty. A more systematic introduction to the science of heuristics can be found in Gigerenzer et al. (2011), Gigerenzer and Gaissmaier (2011), and Gigerenzer and Selten (2001). The spirit of our claims is no news to economists. The fact that their original axiomatic framework is an incomplete formalization of human action was duly noted by von Neumann and Morgenstern (1944):

We repeat most emphatically that our theory is thoroughly static. A dynamic theory would unquestionably be more complete and therefore preferable. But there is ample evidence from other branches of science that it is futile to try to build one as long as the static side is not thoroughly understood. On the other hand, the reader may object to some definitely dynamic arguments which were made in the course of our discussions....We think that this is perfectly legitimate. A static theory deals with equilibria. The essential characteristic of an equilibrium is that it has no tendency to change, i.e. that it is not conducive to dynamic developments. ... For the real dynamics which investigate the precise motions, usually far away from equilibria, a much deeper knowledge of these dynamic phenomena is required. (p. 74)

Relatedly, in his formal treatment of Knightian uncertainty, Bewley (1986) specified that dynamism leads to violation of consistency and introduced inertia as the technical solution. Consistent with Bewley and our emphasis of heuristics on performance rather than coherence, a review by Arkes et al. (2016) found little evidence that violations of coherence are actually costly, that is, have detrimental effects on health, wealth, and happiness or incur other material costs. This null finding also calls for rethinking rationality as defined by purely formal axioms and rules.

Dynamics involve unspecifiable sets of outcomes, or unknown probabilities associated with them. In this paper, we offer heuristics as one form of understanding and modeling choice behavior in such situations. Fast-and-frugal heuristics are simple strategies that can deal with complex situations, utilizing an ecological notion of rationality to replace the logical rationality. More collaboration between economists and psychologists can benefit from findings in this area.

The basic message of this article is this: Uncertainty is different from risk, and its presence requires people to act out of line with the rational prescription for risky situations. One way of dealing with uncertainty that is not reducible to probabilistic risk calculations is by using rules of thumb or heuristics. These heuristics involve partial ignorance. We argue for complementing the study of decision making under risk using probability theory with a systematic study of decision making under uncertainty using formal models of heuristics. Taking uncertainty and heuristics seriously is one way of "venturing beyond the traditional confines of economics," as the epigram to this article calls for.

Acknowledgements Open access funding provided by Max Planck Society. 
Open Access This article is distributed under the terms of the Creative Commons Attribution 4.0 International License (http://creativecommons.org/licenses/by/4.0/), which permits unrestricted use, distribution, and reproduction in any medium, provided you give appropriate credit to the original author(s) and the source, provide a link to the Creative Commons license, and indicate if changes were made.

\section{References}

Akerlof, G. A., \& Shiller, R. J. (2009). Animal spirits. Princeton: Princeton University Press.

Alter, A. L., \& Oppenheimer, D. M. (2006). Predicting short-term stock fluctuations by using processing fluency. Proceedings of the National Academy of Sciences, 103, 9369-9372.

Alter, A. L., \& Oppenheimer, D. M. (2008). Easy on the mind, easy on the wallet: The roles of familiarity and processing fluency in valuation judgments. Psychological Bulletin \& Review, 15, 985-990.

Andersson, P., \& Rakow, T. (2007). Now you see it now you don't: The effectiveness of the recognition heuristic for selecting stocks. Judgment and Decision Making, 2(1), 29-39.

Arkes, H. R., Gigerenzer, G., \& Hertwig, R. (2016). How bad is incoherence? Decision, 3, $20-39$.

Artinger, F. M., \& Gigerenzer, G. (2016). Heuristic pricing in an uncertain market: Ecological and constructivist rationality. Available at SSRN: https://ssrn.com/abstract=2938702. Accessed 25 May 2017.

Berg, N. (2014). Success from satisficing and imitation: Entrepreneurs' location choice and implications of heuristics for local economic development. Journal of Business Research, 67, 1700-1709.

Bewley, T. F. (1986). Knightian Decision Theory: Part I. Yale University, Cowles Foundation Discussion Paper No. 807.

Bewley, T. F. (1987). Knightian Decision Theory: Part II. Yale University, Cowles Foundation Discussion Paper No. 868.

Bikhchandani, S., Hirshleifer, J., \& Riley, J. G. (2013). The analytics of uncertainty and information (2nd ed.). Cambridge: Cambridge University Press.

Borges, B., Goldstein, D. G., Ortmann, A., \& Gigerenzer, G. (1999). Can ignorance beat the stock market? In G. Gigerenzer, P. M. Todd, \& the ABC Research Group., Simple heuristics that make us smart (pp. 59-72). New York: Oxford University Press.

Brandstätter, E., Gigerenzer, G., \& Hertwig, R. (2006). The priority heuristic: Making choices without trade-offs. Psychological Review, 113(2), 409-432.

Colley, A. M., \& Beech, J. R. (1988). Cognition and action in skilled behavior. North-Holland: Elsevier.

Conlisk, J. (1996). Why bounded rationality? Journal of Economic Literature, 34, 669-700.

Daston, L. (1988). Classical probability in the enlightenment. Princeton: Princeton University Press.

DeMiguel, V., Garlappi, L., \& Uppal, R. (2009). Optimal versus naïve diversification: How inefficient is the 1/N portfolio strategy? Review of Financial Studies, 22, 1915-1953.

Dhami, S. (2016). The foundations of behavioral economics analysis. Oxford: Oxford University Press.

Gigerenzer, G. (1996). On narrow norms and vague heuristics: A reply to Kahneman and Tversky. Psychological Review, 103, 592-596.

Gigerenzer, G. (2000). Adaptive thinking: Rationality in the real world. New York: Oxford University Press.

Gigerenzer, G. (2015). On the supposed evidence for libertarian paternalism. Review of Philosophy and Psychology, 6, 363-383. https://doi.org/10.1007/s13164-015-0248-1.

Gigerenzer, G., Fiedler, K., \& Olsson, H. (2012). Rethinking cognitive biases as environmental consequences. In P. M. Todd, G. Gigerenzer, \& the ABC Research Group. Ecological rationality: Intelligence in the world (pp. 80-110). New York: Oxford University Press.

Gigerenzer, G., \& Gaissmaier, W. (2011). Heuristic decision making. Annual Review of Psychology, 62, $451-482$.

Gigerenzer, G., \& Goldstein, D. G. (2011). The recognition heuristic: A decade of research. Judgment and Decision Making, 6, 100-121.

Gigerenzer, G., Hertwig, R., \& Pachur, T. (Eds.). (2011). Heuristics: The foundations of adaptive behavior. New York: Oxford University Press. 
Gigerenzer, G., \& Selten, R. (Eds.). (2001). Bounded rationality: The adaptive toolbox. Cambridge: MIT Press.

Gigerenzer, G., Todd, P. M., \& the ABC Research Group. (1999). Simple heuristics that make us smart. New York: Oxford University Press.

Giocoli, N. (2011). From Wald to Savage: homo economicus becomes a Bayesian statistician. MPRA Paper No. 34117. Online at https://mpra.ub.uni-muenchen.de/34117/. Accessed 25 May 2017.

Goldstein, D. G., \& Gigerenzer, G. (2002). Models of ecological rationality: The recognition heuristic. Psychological Review, 109, 75-90.

Hahn, U., \& Warren, P. A. (2009). Perceptions of randomness: Why three heads are better than four. Psychological Review, 116(2), 454-461.

Hertwig, R., Davis, J. N., \& Sulloway, F. J. (2002). Parental investment: How an equity motive can produce inequality. Psychological Bulletin, 128(5), 228-245.

Hertwig, R., \& Gigerenzer, G. (1999). The "conjunction fallacy" revisited: How intelligent inferences look like reasoning errors. Journal of Behavioral Decision Making, 12, 275-305.

Hoffrage, U. (1995). The adequacy of subjective confidence judgments: Studies concerning the theory of probabilistic mental models. (doctoral dissertation), University of Salzburg, Salzburg.

Kahneman, D. (2011). Thinking, fast and slow. New York: Farrar, Straus and Giroux.

Kahneman, D., Slovic, P., \& Tversky, A. (Eds.). (1982). Judgment under uncertainty: Heuristics and biases. London: Cambridge University Press.

Katsikopoulos, K. V., \& Gigerenzer, G. (2008). One-reason decision-making: Modeling violations of expected utility theory. Journal of Risk and Uncertainty, 37, 35-56.

Kattah, J. C., Talkad, A. V., Wang, D. Z., Hsieh, Y. H., \& Newman-Toker, D. E. (2009). HINTS to diagnose stroke in the acute vestibular syndrome: Three-step bedside oculomotor examination more sensitive than early MRI diffusion-weighted imaging. Stroke; a Journal of Cerebral Circulation, 40(11), 3504-3510.

Keynes, J. M. (1936). The general theory of employment, interest and money. London: Macmillan.

Knight, F. H. (1921). Risk, uncertainty and profit. Dover 2006 unabridged republication of the edition published by Houghton Mifflin Company, Boston and New York.

Lucas, R. E. (2003). Macroeconomic priorities. American Economic Review, 93, 1-14.

Luce, R. D., \& Raiffa, H. (1957). Games and decisions. New York: Dover.

Lynch, P. (1994). Beating the street. New York: Schuster \& Schuster.

Maclusky, D. (2002). Other things equal: Samuelsonian economics. Eastern Economic Journal, 28(3), 425-430.

Marewski, J. N., Pohl, R. F., \& Vitouch, O. (2010). Recognition-based judgments and decisions: Introduction to the special issue (I). Judgment and Decision Making, 5, 207-215.

Marewski, J. N., Pohl, R. F., \& Vitouch, O. (2011). Recognition-based judgments and decisions: Introduction to the special issue (II). Judgment and Decision Making, 6, 1-6.

Mousavi, S., \& Gigerenzer, G. (2011). Revisiting the "Error" in studies of cognitive error. Invited chapter in D. A. Hofmann, and M. Frese (Eds.), Errors in organizations. Society for Industrial and Organizational Psychology (SIOP) Frontiers Series Book. Psychology Press, Taylor and Francis. 97-112.

Mousavi, S., \& Gigerenzer, G. (2014). Risk, uncertainty, and heuristics. Journal of Business Research, 67(8), 1780-1785.

Mousavi, S., Gigerenzer, G., \& Kheirandisch, R. (2016). Rethinking behavioral economics through fastand-frugal heuristics. In R. Frantz, S. H. Chen, K. Dopfer, F. Heukelom, \& S. Mousavi (Eds.), Routledge handbook of behavioral economics (pp. 280-296). London: Taylor \& Francis.

Mousavi, S., \& Kheirandish, R. (2014). Behind and beyond a shared definition of ecological rationality: A functional view of heuristics. Journal of Business Research, 67(8), 1780-1785.

Mousavi, S., Meder, B., Neth, H., \& Kheirandish, R. (2017). Heuristics: Fast, frugal, and effective. In M. Altman (Ed.), Handbook of behavioural economics and smart decision-making. London: Edward Elgar Publishing Ltd.

Neth, H., \& Gigerenzer, G. (2015). Heuristics: Tools for an uncertain world. In R. Scott \& S. Kosslyn (Eds.), Emerging trends in the social and behavioral sciences: An Interdisciplinary, Searchable, and Linkable Resource (pp. 1-18). New York: Wiley. https://doi.org/10.1002/9781118900772. etrds0394.

Ortmann, A., Gigerenzer, G., Borges, B., \& Goldstein, D. G. (2008). The recognition heuristic: A fast and frugal way to investment choice? In C. R. Plott \& V. L. Smith (Eds.), Handbook of experimental 
economics results (Vol. 1, pp. 993-1003)., Handbooks in Economics No. 28 Amsterdam: NorthHolland.

Partridge, D. (1992). Engineering artificial intelligence software. Oxford and Norwood: Intellect Books.

Savage, L. J. (1954). The foundations of statistics. New York: Dover 1972 edition of the original 1954 John Wiley and Sons.

Scheibehenne, B., \& Bröder, A. (2007). Predicting Wimbledon 2005 tennis results by mere player name recognition. International Journal of Forecasting, 23, 415-426.

Schooler, L. J., \& Hertwig, R. (2005). How forgetting aids heuristic inference. Psychological Review, $112,610-628$.

Selten, R. (2001). Game theory and economic behavior: Selected essays. Cheltenham: Elgar.

Serwe, S., \& Frings, C. (2006). Who will win Wimbeldon? The recognition Heuristic in predicting sports events. Journal of Behavioral Decision Making, 19, 321-332.

Shepard, R. N. (1967). Recognition memory for words, sentences, and pictures. Journal of Verbal Learning and Verbal Behavior, 6, 156-163.

Simon, H. A. (1956). Rational choice and the structure of the environment. Psychological Review, 63(2), 129-138.

Simon H. A. (1989). The scientist as problem solver. In D Klahr \& K Kotovsky (Eds.), Complex information processing: The Impact of Herbert A. Simon [21st Carnegie-Mellon symposium on cognition] (pp. 373-98). Hillsdale, NJ: Erlbaum.

Smith, V. L. (2002). 'Constructivist and Ecological Rationality in Economics', available at http://www. nobelprize.org/nobel_prizes/economic-sciences/laureates/2002/smith-lecture.html. Accessed 25 May 2017.

Smith, V. L. (2003). Constructivist and ecological rationality in economics. American Economic Review, 93(3), 465-508.

Smith, V. L. (2008). Rationality in economics: Constructivist and ecological forms. New York: Cambridge University Press.

Thaler, R. H., \& Sunstein, C. R. (2008). Nudge: Improving decisions about health, wealth, and happiness. New Haven: Yale University Press.

Toscani, O. (1997). Die Werbung ist ein lächelndes Aas. Frankfurt: Fischer.

Von Neumann, J., \& Morgenstern, O. (1944). Theory of games and economic behavior. Princeton: Princeton University Press.

Wald, A. (1950). Statistical decision functions. New York: Wiley.

Zeckhauser, R. (2014). New frontiers beyond risk and uncertainty: Ignorance, group decision, and unanticipated themes. In M. J. Machina \& W. K. Viscusi (Eds.), Economics of risk and uncertainty. Elsevier: North-Holland. 